\title{
Effect of Individual Differences in Construal Level on Procrastination: Moderating Role of Intelligence Theories
}

\author{
Miki Terada \\ Faculty of Modern Social Studies, Otemae University, Hyogo, Japan \\ Email: mikiterada.1986@gmail.com
}

How to cite this paper: Terada, M. (2017). Effect of Individual Differences in Construal Level on Procrastination: Moderating Role of Intelligence Theories. Psychology, 8, 517-525.

https://doi.org/10.4236/psych.2017.84032

Received: February 2, 2017

Accepted: March 4, 2017

Published: March 7, 2017

Copyright $\odot 2017$ by author and Scientific Research Publishing Inc. This work is licensed under the Creative Commons Attribution International License (CC BY 4.0).

http://creativecommons.org/licenses/by/4.0/

\section{(c) (i) Open Access}

\begin{abstract}
The relationship between individual differences in construal level and selfcontrol, including procrastination was investigated by examining the following hypotheses. 1) People with high level of construal would procrastinate less when learning a task than those with low level of construal; and 2) theories of intelligence would moderate the effect of construal level on procrastination. These hypotheses were tested by using survey data. Results indicated that people with a low construal level procrastinated more. Results also indicated the moderating role of intelligence theories on the relationship between Behavior Identification Form (BIF) score and procrastination. This study is expected to expand our understanding of construal level theory and individual differences. The findings are also expected to clarify the relationship between construal level and procrastination.
\end{abstract}

\section{Keywords}

Procrastination, Construal-Level, Self-Control, Theories of Intelligence

\section{Introduction}

The purpose of this study was to examine the relationship between individual differences in construal level and self-control, including procrastination, as well as to examine the moderating role of the belief in a particular theory of intelligence on the relationship between construal level and procrastination.

Each of us has procrastinated at least once, which includes not completing a task before a deadline, leaving a task behind, or avoiding facing a task until the deadline. Procrastination of learning tasks is common among university students (Solomon \& Rothblum, 1984). The relationship between procrastination and construal level has been previously investigated (McCrea, Liberman, Trope, 
\& Sherman, 2008). The construal-level theory (CLT) is based on psychological distance (temporal, special, social, and virtual) and suggests that increased psychological distance is associated with more abstract, higher-level construal, because the greater the psychological distance, the sparser would be concrete information, which results in an increased number of abstract construal (Fiedler, Jung, Wänke, \& Alexopoulos, 2012; Liberman \& Trope, 1998; Trope \& Liberman, 2010). A number of studies have reported that the distant future is more likely to be represented in terms of superordinate goals (Liberman \& Trope, 1998), to be placed into a smaller number of broader categories (Liberman, Sagristano, \& Trope, 2002), and to be explained using more abstract traits (Fujita, Eyal, Chaiken, Trope, \& Liberman, 2008; Fujita, Henderson, Eng, Trope, \& Liberman, 2006; Ledgerwood, Wakslak, \& Wang, 2010; Nussbaum, Liberman, \& Trope, 2006). Liberman, Trope, McCrea, \& Sherman (2007) reported that higher-level construal, such as describing things in the abstract (rather than concretely), considering why (rather than how), and first indicating traits implied by an activity, foster a perception of more distal time. McCrea et al. (2008), based on mental associations between the level of abstractness and temporal distance suggested that individuals responding to a questionnaire were less likely to procrastinate when performing the task, if the questionnaire induced a more concrete construal. However, results opposed to those reported by McCrea et al. (2008) could be predicted from the perspective of construal level and self-control.

Why do people procrastinate? One possible reason could be the lack of selfcontrol, including time-planning ability. McCrea et al. (2008) proposed that a high construal level encourages self-control. However, they did not demonstrate that delaying a task was related to the lack of self-control. Furthermore, they designed the tasks in their study to be easy, in order to minimize conflicts related to self-control.

The present research was designed to expand knowledge on the relationship between individual differences in construal level and procrastination as a selfcontrol method.

A previous study has suggested that students that do not procrastinate are more likely to effectively utilize metacognitive strategies, including time-planning and monitoring, compared to students who procrastinate (Wolters, 2003). Moreover, a negative correlation has been reported between time management and procrastination (Lay, 1992; Lay \& Schouwenburg, 1993). Fujita, Trope, Liberman, \& Levin-Sagi (2006) demonstrated that higher-level construal might improve selfcontrol. Activation of high-level construal that captures global, superordinate, and primary features of an event could result in more self-control than activation of low-level construal that captures local, subordinate, or secondary features. Therefore, this study predicted that people with high-level construal would demonstrate lower procrastination related to learning tasks than those with lowlevel construal.

The possibility that individual differences might moderate the relationship 
between construal level and procrastination was also examined. People also procrastinate because of anxiety caused by the fear of failure and the lack of confidence (Beswick, Rothblum \& Mann, 1988; Schouwenburg, 1992; Solomon \& Rothblum, 1984). Moreover, people with anxiety, depression, and low self-esteem are known to procrastinate, because it avoids conflicts and anxiety resulting from fear of failure. Wolters (2003) reported a negative correlation between personality variables, including self-efficacy, and goal achievement orientation, and procrastination. It is possible that effects of the construal level on procrastination are moderated by personality factors that help to avoid facing failure.

It is also known that people hold different theories about intelligence (Dweck \& Leggett, 1988; Dweck, 1999). Theories of intelligence are beliefs that a person might have about his or her academic ability. Some people believe that intelligence is changeable and can be developed (incremental theory), whereas others think of intelligence as being unchangeable and stable (entity theory). Individual differences in beliefs about theories of intelligence have different behavioral outcomes (Dweck, 2006; Dweck \& Leggett, 1988). Belief in incremental intelligence would result in motivation to improve the self by facing challenges, regardless of the level of confidence. Such people would seek opportunities to improve their abilities and motivation by using strategies, even in the face of difficulties and failures. On the other hand, belief in entity theory of intelligence could result in setting good performance goals by placing emphasis on avoiding bad evaluations and obtaining good evaluations. If such people are confident they become motivated to evaluate their abilities, whereas if they have less confidence, their motivation to avoid exposing their inabilities might result in a desire to avoid failures. Therefore, it was hypothesized that the influence of construal level on procrastination would be higher in individuals holding an entity theory of intelligence.

The study examined two hypotheses: 1) People with high level of construal would procrastinate less about learning tasks than people with a low level of construal, and 2) Belief in a particular theory of intelligence would have a moderating role on the effect of construal level on procrastination.

\section{Method}

\subsection{Participants}

Participants were 127 students at Otemae University, in Japan. This survey was conducted for students in psychology lectures. They received the questionnaire and responded during class. Incomplete responses were excluded from the analysis. The data of 124 university students (56 men and 65 women, 3 gender unknown, $M_{\text {age }}=18.48, S D=1.00$ ) were analyzed.

\subsection{Produce}

At the end of the psychology lecture, researcher asked for cooperation in the survey, and distributed the questionnaire. Researcher asked for a take-home answer and collected it in the lecture of the following week, and took note of the 
following points. The cooperation with the investigation is voluntary and not mandatory, your answer is confidential. In addition, students were asked to fill in the student ID number in order to consider the relationship with other data. However, this is not intended to identify individuals or privacy. The collected data is strictly managed, and when it is no longer necessary to verify the data, the information specified by the individual should be discarded from other information.

\subsection{Measures}

\subsubsection{Individual Differences in Construal Level}

The Behavior Identification Form (BIF, Vallacher \& Wegner, 1989), which has been used in previous studies (Freitas, Langsam, Clark, \& Moeller, 2008; Liberman \& Trope, 1998), was used to assess individual differences in action identification. Moreover, Vallacher \& Wegner's (1989) Level of Personal Agency Forced-Choice Questionnaire that was designed to assess stable individual differences in action identification was used to assess individual differences in construal level.

Each of the 25 descriptions in BIF consists of high- and low-level construal statements regarding either distant or near future activities that are presented in pairs and participants are asked to choose the construal they prefer. In the BIF, high and low construal levels are scored as 1 and 0 respectively and the total score is calculated $(\alpha=0.74)$, such that a higher total score indicates a higher construal level. Constant reliability was confirmed on this scale.

\subsubsection{Procrastination}

Nine items of the Aitken Procrastination Scale (Aitken, 1982; Fujita, 2005; $\alpha=$ 0.83) was used. This scale has been used in previous studies (Kandemir, 2014; Ying \& Lv, 2012). As a result of factor analysis by principal factor method and promax rotation, it was confirmed that one-factor solution was valid, and each of the nine items with the highest factor loading was adopted. In the scale, participants are asked to rate the extent to which each item applies to them using a 5-point scale ranging from 1 (Not apply) to 5 (Apply). The mean scores were analyzed. A higher score indicated more frequent procrastination.

\subsubsection{Theories of Intelligence}

Implicit Theories (Fujii \& Uebuchi, 2010; Hong, Chiu, Dweck, Lin, \& Wan, 1999), a scale that includes three items $(\alpha=0.82)$ was used to assess the belief in theories of intelligence. It demonstrated the adequate reliability alphas for previous study were 0.84 (Fujii \& Uebuchi, 2010). Participants were asked to rate the extent to which each item applies to them by using a 6-point scale ranging from 1 (Not apply) to 6 (Apply). The mean scores were analyzed (Blackwell, Trzesniewski, \& Dweck, 2007). A higher score indicated a belief in the entity theory of intelligence.

\subsection{Data Analysis}

First, an independent one-way analysis of variance (ANOVA) was conduct with 
the BIF scores and procrastination. Then, hierarchical regression analysis was conducted to examine the possible moderating role of theories of intelligence on the relationships between BIF and procrastination (Shimizu, 2016).

\section{Results}

As shown in Table 1, BIF was negatively correlated with procrastination, whereas it was not associated with theories of intelligence. Nor were theories of intelligence significantly associated with procrastination. The mean discounted procrastination score was compared with high and low BIF using a one-way ANOVA. As expected, there was a significant main effect of BIF: Discounted procrastination was higher under low construal $(M=3.39, S D=0.69)$ than in high construal level $\left(M=3.09, S D=0.74, F(1,117)=5.02, p=0.02, \eta^{2}=0.04\right)$, indicating that people with low level of construal procrastinated more during a task.

Hierarchical regression analysis indicated a significant main effect of BIF. Moreover, the two-way interaction between the effects of BIF and theories of intelligence on procrastination was significant (Table 2, Figure 1). Simple slope analysis indicated that the effect of BIF on procrastination appeared significantly more in people having an entity $(b=-0.54, p=0.00)$ than an incremental theory of intelligence $(b=-0.06, p=0.72)$. In addition, in people with high construal levels, entity theory of intelligence was more significant on procrastination than incremental theory $(b=-0.18, p=0.02)$, whereas the theory of intelligence had no effect in people with a low construal level $(b=0.02, p=0.74)$. These results supported our hypotheses and indicated that the effect of BIF was significant only for beliefs in entity theory.

Table 1. Correlation matrix.

\begin{tabular}{cccc}
\hline & 1 & 2 & 3 \\
\hline 1) BIF & - & $-0.22^{*}$ & -0.07 \\
2) Procrastination & & - & -0.10 \\
3) Theories of intelligence & & & - \\
\hline
\end{tabular}

Note: ${ }^{*} p<0.05$

Table 2. Results of hierarchical regression analysis.

\begin{tabular}{ccc}
\hline & Step 1 & Step 2 \\
\hline Intercept & $3.242^{* *}$ & $3.234^{* *}$ \\
Theories of intelligence & -0.080 & -0.080 \\
BIF & $-0.311^{*}$ & $-0.306^{*}$ \\
Theories of intelligence ${ }^{*}$ BIF & & $-0.215^{+}$ \\
$R^{2}$ & $0.056^{*}$ & $0.082^{*}$ \\
$\Delta R^{2}$ & & $0.026^{+}$ \\
\hline
\end{tabular}

Note: ${ }^{+} p<0.10 ;{ }^{\star} p<0.05 ;{ }^{*} p<0.01$. 


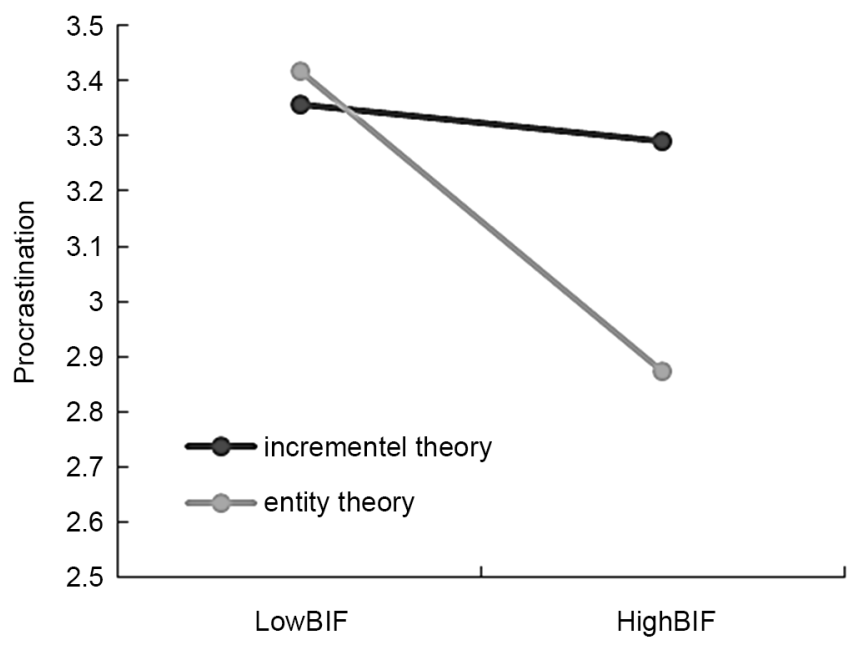

Figure 1. Modulation effect of theories of intelligence on the relationship between BIF and procrastination.

\section{Discussion}

Many students postpone or delay deadlines, which result in reduced motivation and learning achievement. It is known that people procrastinate because of the lack of self-control, and because of the desire to avoid the fear of failure (Beswick et al., 1988; Lay, 1992; Lay \& Schouwenburg, 1993; Schouwenburg, 1992; Solomon \& Rothblum, 1984). This study was designed to examine the relationship between individual differences in construal levels and procrastination, and the moderating role of the theory of intelligence on this relationship. Results indicated that people with a low construal level procrastinated more often, whereas those with a high construal level completed their tasks without procrastinating. Moreover, theories of intelligence moderated the role of construal levels on procrastination, such that a high construal level reduced procrastination only when people believed in the entity theory, which allows them to avoid exposing their inability or face failure.

These findings extend our understanding of the relationships between construal level and procrastination. It is known that differences between low and high-level construal at a conceptual level improve performance requiring both response inhibition and goal maintenance (Schmeichel, Vohs, \& Duke, 2010). Kim, Kang, \& Choi (2014) reported that pleasure is favored in the near future, whereas meaning is favored in the distant future. Therefore, it is possible that individual differences in high-level construal result in less procrastination by suppressing impulses and negative emotions and accomplish their tasks.

The findings of this study lead to suggestion for education. Procrastination in people with a belief in entity intelligence tend to avoid the fear of failure, which can be buffered by the effect of high-level construal. High mental construal instigates a focus on interests during negotiations, which could positively affect outcomes (Wening, Keith, \& Abele, 2015). Especially students that tend to believe in the entity theory and avoid doing their tasks might find it necessary to imagine a long-term plan and develop an interest in essential meaning, rather 
than imagine a short-term plan. They might also want to consider why, more often than how. McCrea et al. (2008) showed the effect of concrete interpretations on procrastination in minimizing conflicts related to self-control when a task was easy. On the other hand, the findings of this study showed that highlevel interpretations might be more effective on procrastination from the perspective of self-control for students who tend to believe in the entity theory.

There are several limitations to the findings of this study. Firstly, the possibility remains that people who often procrastinate tend to have low-level construal. Prior research has suggested that self-regulation results in low-level construal (Bruyneel \& Dewitte, 2012). A longitudinal research design that enables identification of potential casual relationships between individual differences in construal levels and procrastination is required to clarify this issue. Second, although this study investigated procrastination, the effect of learning should have been identified by examining a greater range of indicators. Future research focusing on achievement performance and task deadline expectations are expected to increase our understanding of the relationship between the construal level and learning.

\section{Conclusion}

In conclusion, the results of this study indicated a relationship between individual differences in construal level and procrastination, and the moderating role of the theory of intelligence on the relationship between construal level and procrastination.

\section{References}

Aitken, M. E. (1982). A Personality Profile of the College Student Procrastinator. Ann Arbor: University Microfilms International.

Beswick, G., Rothbluum, E. D., \& Mann, L. (1988). Psychological Antecedents of Student Procrastination. Australian Psychologist, 23, 207-217. https://doi.org/10.1080/00050068808255605

Blackwell, L. S., Trzesniewski, K. H., \& Dweck, C.S. (2007). Implicit Theories of Intelligence Predict Achievement across an Adolescent Transition: A longitudinal study and an intervention. Child Development, 78, 246-263. https://doi.org/10.1111/j.1467-8624.2007.00995.x

Bruyneel, S, D., \& Dewitte, S. (2012). Engaging in Self-Regulation Results in Low-Level Construals. European Journal of Social Psychology, 42, 763-769. https://doi.org/10.1002/ejsp.1896

Dweck, C. S. (1999). Self-Theories: Their Role in Motivation, Personality and Development. Philadelphia, PA: Psychology Press.

Dweck, C. S. (2006). Mindset: The New Psychology of Success. New York: Random House.

Dweck, C. S., \& Leggett, E. L. (1988). A Social Cognitive Approach to Motivation and Personality. Psychological Review, 95, 256-273. https://doi.org/10.1037/0033-295X.95.2.256

Fujii, T., \& Uebuchi, H. (2010). Assessment of Participants' Theories of Intelligence: Reliability and Validity of the Implicit Association Test. The Japanese Journal of Educa- 
tional Psychology, 58, 263-274. https://doi.org/10.5926/jjep.58.263

Fiedler, K., Jung, J., Wänke, M., \& Alexopoulos, T. (2012). On the Relations between Distinct Aspects of Psychological Distance: An Ecological Basis of Construal-Level Theory. Journal of Experimental Social Psychology, 48, 1014-1021. https://doi.org/10.1016/j.jesp.2012.03.013

Freitas, A. L., Langsam, K. L., Clark, S., \& Moeller, S. J. (2008). Seeing Oneself in One's Choices: Construal Level and Self-Pertinence of Electoral and Consumer Decisions. Journal of Experimental Social Psychology, 44, 1174-1179. https://doi.org/10.1016/j.jesp.2008.02.011

Fujita, K., Trope, Y., Liberman, N., \& Levin-Sagi, M. L. (2006). Construal Levels and Self-Control. Journal of Personality and Social Psychology, 90, 351-367. https://doi.org/10.1037/0022-3514.90.3.351

Fujita, K., Eyal, T., Chaiken, S., Trope, Y., \& Liberman, N. (2008). Influencing Attitudes toward Near and Distant Objects. Journal of Experimental Social Psychology, 44, 562 572. https://doi.org/10.1016/j.jesp.2007.10.005

Fujita, K., Henderson, M. D., Eng, J., Trope, Y., \& Liberman, N. (2006). Spatial Distance and Mental Construal of Social Events. Psychological Science, 17, 278-282. https://doi.org/10.1111/j.1467-9280.2006.01698.x

Fujita, T. (2005). A Study of the Relation of Procrastination Behavior and Error Behavior. Nara University of Education Academic Repository, 14, 43-46. http://hdl.handle.net/10105/36

Hong, Y., Chiu, C., Dweck, C. S., Lin, D. M. S., \& Wan, W. (1999). Implicit Theories, Attributions, and Coping: A Meaning System Approach. Journal of Personality and Social Psychology, 77, 588-599. https://doi.org/10.1037/0022-3514.77.3.588

Kandemir, M., İlhan, T., Özpolat, A. R., \& Palanci, M. (2014). Analysis of Academic Self-Efficacy, Self-Esteem and Coping with Stress Skills Predictive Power on Academic Procrastination. Educational Research and Reviews, 9, 146-152. https://doi.org/10.5897/ERR2014.1763

Kim, J., Kang, P., \& Choi, I. (2014). Pleasure Now, Meaning Later: Temporal Dynamics between Pleasure and Meaning. Journal of Experimental Social Psychology, 55, 262270. https://doi.org/10.1016/j.jesp.2014.07.018

Lay, C. (1992). Trait Procrastination and the Perception of Person-Task Characteristics. Journal of Social Behavior and Personality, 7, 483-494. https://www.researchgate.net/publication/272827800

Lay, C., \& Schouwenburg, H. (1993). Trait Procrastination, Time Management, and Academic Behavior. Journal of Social Behavior and Personality, 8, 647-662. https://www.researchgate.net/publication/209836122

Ledgerwood, A., Wakslak, C. J., \& Wang, M. A. (2010). Differential Information Use for near and Distant Decision. Journal of Experimental Social Psychology, 46, 638-642. https://doi.org/10.1016/j.jesp.2010.03.001

Liberman, N., Sagristano, M. D., \& Trope, Y. (2002). The Effect of Temporal Distance on Level of Mental Construal. Journal of Experimental Social Psychology, 38, 523-534. https://doi.org/10.1016/S0022-1031(02)00535-8

Liberman, N., \& Trope, Y. (1998). The Role of Feasibility and Desirability Considerations in near and Distant Future Decisions: A Test of Temporal Construal Theory. Journal of Personality and Social Psychology, 75, 5-18. https://doi.org/10.1037/0022-3514.75.1.5

Liberman, N., Trope, Y., McCrea, S. M., \& Sherman, S. J. (2007). The Effect of Level of Construal on the Temporal Distance of Activity Enactment. Journal of Experimental Social Psychology, 43, 143-149. https://doi.org/10.1016/j.jesp.2005.12.009 
McCrea, S. M., Liberman, N., Trope, Y., \& Sherman, S. J. (2008). Construal Level and Procrastination. Psychological Science, 19, 1308-1314. https://doi.org/10.1111/j.1467-9280.2008.02240.x

Nussbaum, S., Liberman, N., \& Trope, Y. (2006). Predicting the near and Distant Future. Journal of Experimental Psychology: General, 135, 152-161. https://doi.org/10.1037/0096-3445.135.2.152

Schmeichel, B. J., Vohs, K. D., \& Duke, S. C. (2010). Self-Control at High and Low Levels of Mental Construal. Social Psychological and Personality Science, 2, 182-189. https://doi.org/10.1177/1948550610385955

Schouwenburg, H. C. (1992). Procrastinations and Fear of Failure: An Exploration of Reasons for Procrastination. European Journal of Personality, 6, 225-236. https://doi.org/10.1002/per.2410060305

Shimizu, H. (2016). An Introduction to the Statistical Free Software HAD: Suggestions to Improve Teaching, Learning and Practice Data Analysis. Journal of Media, Information and Communication, 1, 59-73.

Solomon, L. J., \& Rothblum, E. D. (1984). Academic Procrastination: Frequency and Cognitive-Behavioral Correlates. Journal of Counseling Psychology, 31, 503-509. https://doi.org/10.1037/0022-0167.31.4.503

Trope, Y., \& Liberman, L. (2010). Construal-Level Theory of Psychological Distance. Psychological Review, 117, 440-463. https://doi.org/10.1037/a0018963

Vallacher, R. R., \& Wegner, D. M. (1989). Levels of Personal Agency: Individual Variation in Action Identification. Journal of Personality and Social Psychology, 57, 660-671. https://doi.org/10.1037/0022-3514.57.4.660

Wening, S., Keith, N., \& Abele, A. E. (2015). High Construal Level Can Help Negotiators to Reach Integrative Agreements: The Role of Information Exchange and Judgement Accuracy. British Journal of Social Psychology, 55, 206-226. https://doi.org/10.1111/bjso.12130

Wolters, C. A. (2003). Understanding Procrastination from a Self-Regulated Learning Perspective. Journal of Educational Psychology, 95, 179-187. https://doi.org/10.1037/0022-0663.95.1.179

Ying, Y., \& Lv, W. (2012). A Study on Higher Vocational College Students' Academic Procrastination Behavior and Related Factors. International Journal of Education and Management Engineering, 2, 29-35. https://doi.org/10.5815/ijeme.2012.07.05

Scientific Research Publishing

Submit or recommend next manuscript to SCIRP and we will provide best service for you:

Accepting pre-submission inquiries through Email, Facebook, LinkedIn, Twitter, etc. A wide selection of journals (inclusive of 9 subjects, more than 200 journals)

Providing 24-hour high-quality service

User-friendly online submission system

Fair and swift peer-review system

Efficient typesetting and proofreading procedure

Display of the result of downloads and visits, as well as the number of cited articles

Maximum dissemination of your research work

Submit your manuscript at: http://papersubmission.scirp.org/

Or contact psych@scirp.org 